\title{
Randomized Prospective Study of Comparison of Intravenous Lornoxicam and Intravenous Fentanyl for Intraoperative and Postoperative Analgesia in Minor to Moderate Ear, Nose, and Throat Surgeries
}

\author{
${ }^{1}$ Yogita Patil, ${ }^{2}$ Priyanka Karnik, ${ }^{3}$ Madhu Garasia
}

\begin{abstract}
Introduction: In day care ear, nose, and throat (ENT) surgeries, patients are admitted and discharged on the same day, provided they are free of anesthetic and surgical side effects. In this prospective randomized study, we compared the perioperative analgesic efficacy and side effects like nausea, sedation, and respiratory depression 24 hours postsurgery with use of lornoxicam and fentanyl.
\end{abstract}

Background: Although opioids are traditionally used in managing postoperative pain, their side effects like nausea, respiratory depression, sedation, constipation, urinary retention, and itching limit their use. This may result in delayed discharge and prolonged hospital stay in day care surgery. Nonsteroidal anti-inflammatory drugs have central and peripheral analgesic effects, anti-inflammatory properties, and relatively better tolerability with few side effects. ${ }^{1,2}$.

Materials and methods: After institutional Ethics Committee approval, 100 patients were randomly allocated into two groups (50 each). Various parameters like intraoperative heart rate, blood pressure, postoperative pain, analgesic requirement, respiratory depression, sedation, and nausea scores were studied.

Statistical analysis: Analysis of quantitative data with unpaired $t$-test and qualitative data with chi-square test.

Results: The heart rate was higher in the fentanyl group (B) than in the lornoxicam group $(A)$ during reversal and extubation, with $p$-value $<0.05$. The visual analog scale scores were higher in group $(B)$ than in group $(A)$, with $p$ value $<0.05$ for 2 hours. Need for rescue analgesia was more in group $(B)$ with 51 patients within hour of surgery and 11 patient in group $(A)$ up to 8 hours postsurgery. The $p$ values for nausea scores were 0.0001 , 0.0011 , and 0.0001 at $30 \mathrm{~min}, 1$ hour, and 2 hours, respectively, and were higher in group (B). The $p$ value for sedation score was 0.002 . The respiratory rate was lower in group (B) up to 8 hours postsurgery.

Conclusion: Lornoxicam has good intraoperative and better postoperative analgesia as compared with fentanyl in minor

\footnotetext{
${ }^{1}$ Associate Professor, ${ }^{2}$ Resident, ${ }^{3}$ Professor

${ }^{1-3}$ Department of Anaesthesia, King's Edward Memorial Hospital and Seth GS Medical College, Mumbai, Maharashtra, India
}

Corresponding Author: Yogita Patil, Associate Professor Department of Anaesthesia, King's Edward Memorial Hospital and Seth GS Medical College, Mumbai, Maharashtra, India Phone: +919833935747, e-mail: yogitapatil76@gmail.com to moderate ENT surgeries. The need for rescue analgesia is less in lornoxicam group. Lornoxicam was also found to have a lower incidence of side effects like nausea, sedation, and respiratory depression.

Keywords: Fentanyl, Lornoxicam, Minor to moderate surgery, Respiratory depression.

How to cite this article: Patil Y, Karnik P, Garasia M. Randomized Prospective Study of Comparison of Intravenous Lornoxicam and Intravenous Fentanyl for Intraoperative and Postoperative Analgesia in Minor to Moderate Ear, Nose, and Throat Surgeries. Res Inno Anaesth 2016;1(1):10-14.

Source of support: Nil

Conflict of interest: None

\section{INTRODUCTION}

Ear, nose, and throat (ENT) surgeries like tympanoplasty, modified radical mastoidectomy, functional endoscopic sinus surgery (FESS), tonsillectomy, etc. are considered minor to moderate surgeries requiring shorter hospital stay. ${ }^{3,4}$ These are day care surgeries in which patients can be admitted and discharged on the same day, provided they are free of anesthetic and surgical side effects. The ability to deliver a safe and cost-effective general anesthetic with minimal side effects and rapid recovery is a demand of day care surgery. Pain and emesis are the two major complaints after such ENT surgeries.

In this prospective randomized study, we compared the intraoperative and postoperative analgesic efficacy and the incidence of side effects like nausea, sedation, and respiratory depression up to 24 hours postsurgery with use of lornoxicam and fentanyl.

\section{AIMS AND OBJECTIVES}

\section{Primary Objectives}

To compare the efficacy of intraoperative and postoperative analgesia of intravenous (IV) lornoxicam and IV fentanyl in minor to moderate ENT surgeries by monitoring

- Visual analog scale (VAS) score

- Sedation score

- Respiratory depression

- Rescue analgesia 


\section{Secondary Objectives}

To monitor side effects and adverse effects of IV lornoxicam and IV fentanyl by observing

- Nausea and vomiting scores and

- Adverse effects if any

\section{MATERIALS AND METHODS}

\section{Methodology}

Sample size was taken as 50 patients for each group in order to detect a difference in VAS score of 0.7. The $\alpha$ error was assumed to be 0.05 , power of $90 \%$, and dropout rate of $50 \%$. Randomization was done using computer-generated randomization with website www.randomisation.com.

\section{Inclusion Criteria}

- American Society of Anesthesiologists grade I and II

- Patient of either sex: male or female

- Patients aged between 18 and 60 years

Undergoing ENT surgeries like tonsillectomy, FESS, polypectomy, excision of ENT lesions like nodules, cyst.

\section{Exclusion Criteria}

- Patients with body mass index $>30 \%$

- Drug or alcohol abuse

- Known allergy to nonsteroidal anti-inflammatory drugs or tramadol

- Any contradictions for opioid use

- Coagulation disorders

- Pregnant and lactating mothers

- Patients with hepatic or renal dysfunction

- Major ENT surgery

\section{Study Procedure}

After obtaining institutional ethical committee approval and informed written consent, 100 patients were randomly allocated into two groups each:

Group A: Patients received lornoxicam $8 \mathrm{mg}$ half an hour before induction of anesthesia.

Group B: Patients received $100 \mu \mathrm{g}$ fentanyl at induction of anesthesia.

Premedication with Inj. midazolam $0.03 \mathrm{mg} / \mathrm{kg}$ was given. Anesthesia was induced with propofol $2 \mathrm{mg} / \mathrm{kg}$ IV followed by vecuronium $0.1 \mathrm{mg} / \mathrm{kg}$ to facilitate endotracheal intubation. Anesthesia was maintained with $\mathrm{O}_{2}+$ nitrous oxide (50:50) and sevoflurane or propofol infusion. Patients were mechanically ventilated and normocapnia was maintained. Monitoring was done with electrocardiogram, noninvasive blood pressure monitor, oxygen saturation and end tidal carbon dioxide.
Supplementary fentanyl $0.5 \mu \mathrm{g} / \mathrm{kg}$ was given as required in all groups only if there was $>20 \%$ increase in mean arterial pressure (MAP) or heart rate than preinduction values. Thus, opioid sparing effect of lornoxicam was studied. At the end of surgery, patient was reversed and extubated. All patients were monitored with VAS and sedation score at $0.5,1,2,4,8,12,24$ hours by the anesthetist who was blinded about the drugs given to the patient. The incidence of postoperative nausea and vomiting or any adverse event was recorded. The first need for rescue analgesia was recorded from the time of administration of the study drug. The rescue analgesia was Inj Tramadol $50 \mathrm{mg}$ IV.

Pain intensity was measured by using $0-10 \mathrm{~cm}$ VAS:

0 : no pain

2 to 4 : mild pain

5 to 7 : moderate pain

7 to 10 : severe pain

Sedation was evaluated by a 5-point Ramsay sedation scoring system:

1: Patient anxious and agitated or restless or both

2: Patient cooperative, oriented, and tranquil

3: Patient responds to commands only

4: Brisk response to a light glabellar tap or auditory stimulus

5: Sluggish response to a light glabellar tap or auditory stimulus

6: No response to stimuli mentioned in 4 and 5

Nausea was assessed as

0 : None

1: Mild

2: Moderate

3: Severe/request for treatment

Respiratory depression was defined as respiratory rate of $<10 / \mathrm{min}$.

\section{Statistical Analysis}

Student's unpaired $t$-test (for comparison of numerical data) and Chi-square test (for comparison of categorical data) were used for statistical analysis. Difference was considered significant when the p-value was found to be less than 0.05 .

\section{DISCUSSION}

The use of an opioid, even short acting, can be associated with adverse effects, which may not be acceptable to patients scheduled for day care surgery. Lornoxicam produces significant opioid sparing effects. It decreased 24-hour total opioid consumption and increases the time to first analgesic use. ${ }^{3-6}$

In our study with respect to demographic variables both the groups were comparable. The MAP value 
was found to increase in group B during reversal and extubation and p-value was found to be 0.010 and 0.001 during reversal and extubation respectively (Table 1).

In a study by Arslan et al, 40 patients undergoing thyroidectomy were randomized into two groups: Group L received $8 \mathrm{mg}$ of lornoxicam and Group $\mathrm{P}$ received $4 \mathrm{ml}$ normal saline. The time to first analgesic requirement was significantly longer in Group L. Pain scores were significantly lower in Group L compared with Group P up to 18 hours $(\mathrm{p}<0.05)$. Pain scores at 18 and 24 hours were significantly lower in Group L ( $p=0.003, p<0.0001$ respectively). The 24-hour total tramadol consumption of Group L was 60\% less compared to Group P.,

In a double-blind, randomized, placebo-controlled study by Inan et al, the effect of lornoxicam administration (32 mg/48 hours) on morphine consumption and drugrelated side effects was investigated in elderly patients undergoing total knee replacement; $24 \mathrm{mg}$ of lornoxicam for the first 24 hours and $8 \mathrm{mg}$ of lornoxicam used for the second 24 hours reduced morphine consumption and side effects related to morphine consumption without additional side effects of lornoxicam..$^{9,10}$

The maximum value of VAS score (Table 2) was found to be higher in group $B$ than in group $A$. The $p$ value was $0.0001,0.0001$ and 0.029 at $30 \mathrm{~min}, 1$ hour and 2 hours, implying statistical significance. The need for rescue analgesia, that is, Inj. Tramadol $50 \mathrm{mg}$, was higher in fentanyl group with $32(64 \%)$ out of 50 patients requiring it as compared with only $11(22 \%)$ in the lornoxicam group. The time to first analgesic requirement in fentanyl group peaks at 1 hour with 13 patients needing rescue analgesia, (Table 3) while in lornoxicam group it peaks at 8 hours with 5 patients needing it, showing better analgesia with group A. The need remains high in group B at 2 hours with nine patients requiring tramadol as compared with two patients in group A.

In a study by Ertugrul et al, 23 patients posted for extracorporeal shock wave lithotripsy (ESWL) were randomly allocated to receive either a bolus of $1 \mu \mathrm{g} / \mathrm{kg}$ fentanyl followed by a continuous infusion of propofol at a rate of $1 \mathrm{mg} / \mathrm{kg} / \mathrm{hr}$ or a bolus of $8 \mathrm{mg}$ lornoxicam followed by a continuous infusion of propofol at a rate of $1 \mathrm{mg} / \mathrm{kg} / \mathrm{hr}$. Pain intensity, level of sedation, and analgesic requirement were recorded; the sedation scores were significantly higher in fentanyl than lornoxicam group $(\mathrm{p}<0.05) .{ }^{10-12}$

In our study, the mean sedation score was higher in fentanyl group $(2.26 \pm 0.44)$ than in lornoxicam group (2) at $30 \mathrm{~min}$ with p value of 0.025 at $30 \mathrm{~min}$. None of the patients remained deeply sedated postoperatively (Table 4). Only one patient received tramadol as rescue analgesia.

In the randomized prospective study by Daabis et al comparing analgesic efficacy of lornoxicam and fentanyl in day care ENT surgeries, nausea developed in $25.7 \%$ patients in the fentanyl group, $20 \%$ patients in $8 \mathrm{mg}$

Table 1: Comparison between study groups for pulse rate

\begin{tabular}{|c|c|c|c|c|c|c|}
\hline \multirow[b]{2}{*}{ Pulse rate (per min) } & \multicolumn{2}{|c|}{ Group A } & \multicolumn{2}{|c|}{ Group B } & \multirow[b]{2}{*}{$p$-value } & \multirow[b]{2}{*}{ Association } \\
\hline & Minimum & Maximum & Minimum & Maximum & & \\
\hline Preoperative & 66.00 & 99.00 & 0.003 & 95.00 & 0.003 & $\mathrm{~S}$ \\
\hline Induction & 80.00 & 116.00 & 0.894 & 113.00 & 0.894 & NS \\
\hline Incision & 69.00 & 98.00 & 0.988 & 98.00 & 0.988 & NS \\
\hline $30 \mathrm{~min}$ & 57.00 & 89.00 & 0.368 & 88.00 & 0.368 & NS \\
\hline $1 \mathrm{hr}$ & 64.00 & 86.00 & 0.707 & 80.00 & 0.707 & NS \\
\hline $1 \mathrm{hr} 30 \mathrm{~min}$ & 58.00 & 86.00 & 0.228 & 84.00 & 0.228 & NS \\
\hline $2 \mathrm{hr}$ & 62.00 & 81.00 & 0.098 & 85.00 & 0.098 & NS \\
\hline Closure & 67.00 & 92.00 & 0.020 & 89.00 & 0.020 & S \\
\hline Reversal & 78.00 & 102.00 & 0.004 & 115.00 & 0.004 & $S$ \\
\hline Extubation & 84.00 & 116.00 & 0.001 & 123.00 & 0.001 & S \\
\hline
\end{tabular}

S: Significant; NS: Not significant

Table 2: Comparison between study groups for visual analog scale (VAS)

\begin{tabular}{|c|c|c|c|c|c|c|c|}
\hline \multirow[b]{2}{*}{ Post-op VAS } & \multicolumn{2}{|c|}{ Group A } & \multicolumn{2}{|c|}{ Group B } & \multirow[b]{2}{*}{ Mann-Whitney test } & \multirow[b]{2}{*}{$p$-value } & \multirow[b]{2}{*}{ Association } \\
\hline & Minimum & Maximum & Minimum & Maximum & & & \\
\hline $30 \mathrm{~min}$ & 0.00 & 2.00 & 0.00 & 5.00 & 4.759 & 0.0001 & $S$ \\
\hline $1 \mathrm{hr}$ & 0.00 & 5.00 & 0.00 & 7.00 & 4.364 & 0.0001 & $S$ \\
\hline $2 \mathrm{hrs}$ & 0.00 & 5.00 & 0.00 & 7.00 & 2.189 & 0.029 & $S$ \\
\hline $4 \mathrm{hrs}$ & 0.00 & 5.00 & 0.00 & 6.00 & 0.210 & 0.833 & NS \\
\hline $8 \mathrm{hrs}$ & 0.00 & 6.00 & 0.00 & 5.00 & 0.452 & 0.652 & NS \\
\hline $12 \mathrm{hrs}$ & 0.00 & 4.00 & 0.00 & 5.00 & 0.038 & 0.970 & NS \\
\hline $24 \mathrm{hrs}$ & 0.00 & 3.00 & 0.00 & 4.00 & 0.765 & 0.444 & NS \\
\hline
\end{tabular}

S: Significant; NS: Not significant 
Table 3: Comparison of need for rescue analgesia at each time point

\begin{tabular}{lll}
\hline Duration & Group $A$ & Group B \\
\hline $30 \mathrm{~min}$ & 0 & 3 \\
$1 \mathrm{hr}$ & 1 & 13 \\
$2 \mathrm{hrs}$ & 2 & 9 \\
$4 \mathrm{hrs}$ & 1 & 4 \\
$8 \mathrm{hrs}$ & 5 & 1 \\
$12 \mathrm{hrs}$ & 2 & 2 \\
$24 \mathrm{hrs}$ & 0 & 0 \\
\hline
\end{tabular}

lornoxicam group, and only $8.6 \%$ patients with $16 \mathrm{mg}$ lornoxicam (Table 5). ${ }^{3}$

In our study, the maximum nausea score is 2 in fentanyl group and 1 in lornoxicam group at 30 min and 1 hour. Moderate nausea was seen in $22 \%$ of patients in fentanyl group, while mild nausea was seen in lornoxicam group at $30 \mathrm{~min}$. The $\mathrm{p}$ value was found to be $0.0001,0.0011$, and 0.0001 at $30 \mathrm{~min}, 1$ hour, and 2 hours respectively. Out of 11 patients who experienced nausea at $30 \mathrm{~min}$ in the fentanyl group, only one patient had received Inj. tramadol as rescue analgesia.

In a study by Ertugrul et $\mathrm{al}^{12}$ in 23 patients posted for ESWL, the incidence of oxygen supplementation and respiratory depression was found to be lower in lornoxicam group than in fentanyl group.

The minimum respiratory rate was 9 in the fentanyl group at $30 \mathrm{~min}$, while it was 12 in lornoxicam group. The mean respiratory rate was lower in fentanyl group than in lornoxicam group at $30 \mathrm{~min}, 1$ hour, 2 hours, 4 hours, and 8 hours, but not below 10 breaths per minute and nobody required treatment for it. The $p$-value was less than 0.05 at all above points, implying statistical significance. Thus, our study shows that there is always possibility of postoperative respiratory depression when opioids are used intraoperatively for analgesia. So in day care surgery, it is always better to use ultra-shortacting opioids or if possible avoid intraoperative opioids (Table 6).

Table 4: Comparison between study groups for sedation score

\begin{tabular}{|c|c|c|c|c|c|c|c|}
\hline \multirow[b]{2}{*}{ Post-op sedation score } & \multicolumn{2}{|c|}{ Group A } & \multicolumn{2}{|c|}{ Group B } & \multirow[b]{2}{*}{ Mann-Whitney test } & \multirow[b]{2}{*}{$p$-value } & \multirow[b]{2}{*}{ Association } \\
\hline & Minimum & Maximum & Minimum & Maximum & & & \\
\hline $30 \mathrm{~min}$ & 2.00 & 2.00 & 2.00 & 3.00 & 2.240 & 0.025 & $\mathrm{~S}$ \\
\hline $1 \mathrm{hr}$ & 2.00 & 2.00 & 2.00 & 3.00 & 0.689 & 0.491 & NS \\
\hline $2 \mathrm{hrs}$ & 2.00 & 2.00 & 2.00 & 2.00 & 0.000 & 1.000 & NS \\
\hline $4 \mathrm{hrs}$ & 2.00 & 2.00 & 2.00 & 2.00 & 0.000 & 1.000 & NS \\
\hline $8 \mathrm{hrs}$ & 2.00 & 2.00 & 2.00 & 2.00 & 0.000 & 1.000 & NS \\
\hline $12 \mathrm{hrs}$ & 2.00 & 2.00 & 2.00 & 2.00 & 0.172 & 0.863 & NS \\
\hline $24 \mathrm{hrs}$ & 2.00 & 2.00 & 2.00 & 2.00 & 0.000 & 1.000 & NS \\
\hline
\end{tabular}

S: Significant; NS: Not significant

Table 5: Comparison between study groups for nausea score

\begin{tabular}{|c|c|c|c|c|c|c|c|}
\hline \multirow[b]{2}{*}{ Post-op nausea } & \multicolumn{2}{|c|}{ Group A } & \multicolumn{2}{|c|}{ Group B } & \multirow[b]{2}{*}{ Mann-Whitney test } & \multirow[b]{2}{*}{$p$-value } & \multirow[b]{2}{*}{ Association } \\
\hline & Minimum & Maximum & Minimum & Maximum & & & \\
\hline $30 \mathrm{~min}$ & 0.00 & 1.00 & 0.00 & 2.00 & 3.974 & 0.0001 & $\mathrm{~S}$ \\
\hline $1 \mathrm{hr}$ & 0.00 & 1.00 & 0.00 & 2.00 & 3.268 & 0.0011 & $S$ \\
\hline $2 \mathrm{hrs}$ & 0.00 & 1.00 & 0.00 & 1.00 & 3.964 & 0.0001 & $S$ \\
\hline $4 \mathrm{hrs}$ & 0.00 & 1.00 & 0.00 & 1.00 & 1.723 & 0.0848 & NS \\
\hline $8 \mathrm{hrs}$ & 0.00 & 0.00 & 0.00 & 1.00 & 1.034 & 0.3011 & NS \\
\hline $12 \mathrm{hrs}$ & 0.00 & 1.00 & 0.00 & 0.00 & 0.517 & 0.6051 & NS \\
\hline $24 \mathrm{hrs}$ & 0.00 & 1.00 & 0.00 & 0.00 & 0.345 & 0.7303 & NS \\
\hline
\end{tabular}

S: Significant; NS: Not significant

Table 6: Comparison between study groups for post-op respiratory rate

\begin{tabular}{|c|c|c|c|c|c|c|c|}
\hline \multirow{2}{*}{$\begin{array}{l}\text { Post-op respiratory } \\
\text { rate (per min) }\end{array}$} & \multicolumn{2}{|c|}{ Group A } & \multicolumn{2}{|c|}{ Group B } & \multirow[b]{2}{*}{ Unpaired t-test } & \multirow[b]{2}{*}{$p$-value } & \multirow[b]{2}{*}{ Association } \\
\hline & Minimum & Maximum & Minimum & $\overline{\text { Maximum }}$ & & & \\
\hline $30 \mathrm{~min}$ & 12.00 & 18.00 & 9.00 & 18.00 & 6.773 & 0.000 & $\mathrm{~S}$ \\
\hline $1 \mathrm{hr}$ & 12.00 & 18.00 & 10.00 & 18.00 & 3.396 & 0.001 & $\mathrm{~S}$ \\
\hline $2 \mathrm{hrs}$ & 12.00 & 19.00 & 11.00 & 19.00 & 3.830 & 0.0001 & $\mathrm{~s}$ \\
\hline $4 \mathrm{hrs}$ & 14.00 & 19.00 & 12.00 & 19.00 & 4.460 & 0.0001 & $S$ \\
\hline $8 \mathrm{hrs}$ & 13.00 & 19.00 & 12.00 & 18.00 & 2.194 & 0.031 & S \\
\hline $12 \mathrm{hrs}$ & 14.00 & 19.00 & 12.00 & 19.00 & 1.248 & 0.215 & NS \\
\hline $24 \mathrm{hrs}$ & 12.00 & 19.00 & 12.00 & 19.00 & 0.126 & 0.900 & NS \\
\hline
\end{tabular}

RR: respiratory rate.; S: Significant; NS: Not significant 


\section{CONCLUSION}

From the present study, it can be concluded that lornoxicam has good intraoperative and better postoperative analgesia as compared with fentanyl in minor to moderate ENT surgeries. The intraoperative heart rate and MAP was higher in fentanyl group than in lornoxicam group during reversal and extubation. The mean VAS score were higher in fentanyl group than in lornoxicam group. The need for rescue analgesia was in 32 out of 50 patients $(64 \%)$ in the fentanyl group, while it was 11 out of 50 patients $(22 \%)$ in lornoxicam group. Lornoxicam was also found to have a lower incidence of side effects like nausea, sedation, and respiratory depression.

Thus, IV lornoxicam can be considered as a safe alternative for management of intraoperative and postoperative pain in minor to moderate ENT surgeries.

\section{REFERENCES}

1. McCrory CR, Sten G, Lindahl GE. Cyclooxygenase inhibition for postoperative analgesia. Anesth Analg 2002 Jul;95(1): 169-176.

2. Radhofer-Welte S, Rabasseda X. Lornoxicam, a new potent NSAID with an improved tolerability profile. Drugs Today (Barc) 2000 Jan;36(1):55-76.

3. Daabis M, Al Sherbiny M, Al Nimar R. Analgesic efficacy in day case ENT surgery: the efficacy of lornoxicam. Br J Med Pract 2009;2(3):46-50.
4. Arslan M, Tuncer B, Babacan A, Taneri F, Karadenizli Y, Onuk E, Ege B. Postoperative analgesic effects of lornoxicam after thyroidectomy: a placebo controlled randomized study. Agri 2006 Apr;18(2):27-33.

5. Inan N, Ozcan N, Takmaz SA, Ozcan A. Efficacy of lornoxicam in postoperative analgesia after total knee replacement surgery. Agri 2007 Apr;19(2):38-45.

6. Mowafi HA, Telmessani L, Ismail SA, Naguib MB. Preoperative lornoxicam for pain prevention after tonsillectomy in adults. J Clin Anesth 2011 Mar;23(2):97-101.

7. Soliman WR, Moussa AA, Nassef MA. Preoperative lornoxicam attenuates the haemodynamic response to intubation in elderly. Eur J Anaesthesiol 2007 Jun;24:193.

8. Rathmell, JP.; Fields, HL. Harrison's principle of internal medicine. Pain: pathophysiology and management. 14th ed. 1998. p. 53-58.

9. Norholt ES, Pederson S, Larsen U. Pain control after dental surgery: a double blind, randomized controlled trial of lornoxicam versus morphine. Pain 1996 Oct;67(2-3): 335-343.

10. Balanika M, Tsitsika M, Wilczynski W. The use of lornoxicammeperidine combination for post operative analgesia. Eur J Anaesthesiol 2000;17:771-778.

11. Staunstrup H, Ovesen J, Larsen UT, Elbaek K, Larsen U, Krøner K. Efficacy and tolerability of lornoxicam versus tramadol for post operative pain. J Clin Pharmacol 1999 Aug;39(8):834-841.

12. Ertugrul F, Kayacan N, Erdogan T, Onder G, Karsli B, Danisman A. The comparison of lornoxicam-propofol and fentanyl-propofol combinations on ESWL. Eur J Anaesthesiol 2005 May;22:15. 